soning, quinin should be given in large doses, fifteen to thirty grains a day. If not tolerated by the stomach, it may be given by rectal enemata. In desperate cases the propriety of transfusion of blood may be presented for consideration. But experience shows that this remedial measure only too often serves to revive a bleeding that had merely subsided so long as the veins were empty. Better results have been obtained from the hypodermic injection of one or two pints of a salt solution of the strength of three-quarters of 1 per cent., or three and a half grains of salt to the ounce of distilled water. This solution may be very easily injected into the loose areolar tissue in either flank of the body, whence it is rapidly absorbed into the lymphatic vessels.

\section{A PROPOSED TREATMENT FOR CONSUMPTIVES.}

BY H. T. TILLOTSON, M.D. chICAGO.

Since Koch's discovery of the tubercle bacillus, and its manner of communicability, there has resulted in the medical profession, and latterly in the laity, efforts for public defense against infection. The means primarily adopted by the profession, were for the relief of the individual, as cod liver oil, hypophosphites, creosote, sulphureted hydrogen, Koch's tuberculin, and many others, all of which have been demonstrated practical failures in the treatment of pulmonary consumption. These failures have caused the laity, as city and State governments, to contemplate isolation. Modern isolation is again developing the hospital character, with a pesthouse tendency. Compulsory isolation creates a true pesthouse, to prove as unsatisfactory as prior examples, in dealing with this disease. So-called isolation is a misnomer. A befitting appelation is aggregation, and will be so used in speaking of institutions for consumptives. Voluntary isolation or aggregation is public or private. The public institutions are patronized by the poorer class, supported and controlled by the public, and necessarily located in or near cities. If not positively injurious, they are certainly of little value as curative agents, and could as well be called poor houses.

The private institution is much better, and known under various names, as homes, sanitaria, hotels, springs, etc. They are patronized by the financially fortunate. They are located in all parts of the country, taking advantage of all available climatic conditions and giving accomodation to all diseases, the only requisite for admission being the price.

Modern isolation means an aggregation of tubercular individuals, under one roof or in one colony, in all stages of the disease, causing a constant series of reinfections among the inmates, delaying recovery or rendering it impossible. It is a recognized truism that pulmonary tubercular cases are dangerous to inmates of general hospitals, and are denied admission. Is it logical to collect these infected individuals between four walls, to become a constant source of danger to each other and expect them to recover?

A striking example of irrational methods for public preservation from infection is the late contention in Boston, over the site of a Free Home for Consumptives, under municipal auspices. It was proposed to erect a cheap, faulty, brick building $60 \times 100$ feet, 4 stories, on Quincy street, in a residence district. The inevitable result will be a germ factory with a prolific out-put. It will remove perambulating patients from nature's remedies, sunshine, free air and exercise, to place them in a veritable culture medium, or incubat. ing oven, with questionable fresh air, administered in medicinal form and doses; with sunshine a rarity, a decrease in tissue resistance and leucocytic activity, and increase in mortality. Here is neither public preservation nor so-called isolation, but simply aggregation, exhibiting a clearly defined determination to defend the public at the expense of the inmates. Such institutions may be profitably used as a last home for hopeless cases only, and should be located in surburban districts. All tubercular aggregations, whether in city or country, should be condemned as improper or perilous for walking cases who may be benefited or recovered by climatic treatment.

Another and very important objection to aggregation is "mental infection." By mental infection, I mean the acquisition of a. saturnine mentality, whereby a primarily favorable case becomes unfavorable by association with other invalids, giving ready credence to idle gossip, the daily comparison of symptoms, resulting in unfavorable comments; some make constant use of the clinical thermometer, shaking down the mercurial column with professional dexterity. Their daily sedentary life and habits compel their brains unceasingly to dwell upon their infirmity, subjecting them to foolish fears and apprehesions and erroneous interpretation of trivial transitory symptoms. These invalids repair to some health resort with the expectation of relief by water, air or some other invisible means. They sit around the hotel office or town, impatiently waiting for the expected relief, which is delayed by reinfection; become despondent, which frequently initiates collapse. Many remain but a short time in any one place, producing a floating, shifting, tubercular population, found principally throughout the west and southeast. They patronize the railroads and hotels, leaving infection possible in all directions. The mental condition of female patients frequently become highly distressing from association, gossip, or ennui.

These strong objections to aggregations of consumptives were revealed to me forcefully while a member of such colonies, in the capacity, of invalid, resulting in some definite conclusions and suggestions for improvement. The substitute for isolation or aggregation may be divided into three classes, the first, a private boarding house or cottage plan, offers a much nearer approach to isolation, and avoids many of the evils of large institutions. The next, a still more promising plan, with almost true isolation, is the ranch life. Thousands of ranchers throughout the arid west will give a comfortable home to invalids, supplying the necessary sterile surroundings, exercise and climate. There should be but one invalid permitted on each ranch. Board and lodging are nominal, no more than eastern rates. Many find employment on stock ranches, because unable to afford residence at a hotel or sanitarium, and are greatly benefited thereby. The third class may be known as "camping" parties, and offers greater inducements than all others. A dry climate being the accepted standard, it is necessary to look southwest or west for it. A dry climate means a great diminution in vegetation. Often absolute deserts greet an outraged, esthetic eye, especially when exhibiting a vigorous sandstorm.

Many of the profession have found serious objection to western plains as an asylum for consumptives, 
because sandstorms occur. I believe they are no particular detriment. The sand and fine atmospheric dust is sterilized by sun and pure air; and carries no infection, unless occuring in a large town or city. The thirsty, hungry soil greedily devours all moisture from sputa and other contaminating material, and the almost constant sunshine does the rest. The dry climate permits almost indiscriminate out-door exposure, without deleterious effects. The temperature is equitable as any to be found.

Form a party of four to eight invalids under the supervision of a physician, employ a cook and drivers, purchase all necessary paraphernalia, and leave the towns to lead a nomadic life under canvas, with diversions of hunting and fishing, sure to relieve the mind of morbid occupations, supplying sufficient compulsory exercise to stimulate a wholesome appetite and a rapid improvement in all symptoms, in all reasonable cases. The expenses of such a trip of four or five months will be no more than ordinary western hotel charges, and much less than expenses at some sanitariums and resorts. Much more could be said on this subject of a practical nature.

The dangers of aggregations caused me to adopt the camping plan, resulting in recovery in four or five months. I prolonged my outdoor life, through choice, for over two years. I rented a common farm-wagon and team, and made an extensive trip in western New Mexico, sleeping on the ground at night, preparing my own meals, hunting and fishing when opportunity presented, obtaining constant occupation driving, care of horses and other necessary duties. My next trip was also in a wagon across southern Chihuahua and Durango, Mexico, where our hardships were sometimes pronounced. The following winter was partly spent in the saddle near the summit of the Sierra Madra mountains. The summer of 1894 was devoted to the saddle and wagon, in northern California. The following spring and summer occurred my last wagon trip, from West Port on the Pacific Coasi, across California, Nevada, Idaho, the Yellowstone National Park, to Cinnabar, Montana. By this plan I was enabled to move my sanitarium daily; every night found me on sterilized ground, never infected or host to tubercle bacilli, a plan compelling me to seek health instead of waiting for her to seek me. I enjoyed to the fullest extent nature's panorama, revealed in daily sections, and the pleasurable excitement of plentiful hunting and fishing, sound sleep and a ravenous appetite. The almost perpetual sunshine, dry air, high altitude, unavoidable exercise and exhilaration were the components of the prescription, causing my own recovery promptly, permiting my subsequent residence in Chicago in the best of health.

This is a prescription eagerly and rapidly assimilated, greatly desired by the healthy, and positively curative in others.

6301 Yale Street.

\section{A FEW INSTANCES OF THE USE OF PRO- TONUCLEIN IN CONTAGIOUS AND NON.CONTAGIOUS DISEASES.}

\section{BY WESLEY G. BAILEY, M.D.}

$$
\text { PEKIN, IIJL. }
$$

This comparatively new substance has played an important rôle in the armamentarium of the up-todate physician for at least eighteen months or two years. These two years have conclusively proved that protonuclein has come to stay, as its action is not ephemeral; for certain diseases are not the terrors either to the minds of the laity or profession since its introduction. To be practical, it is necessary or usual to illustrate one's points by the citation of cases. We will presint a few for your consideration:

Case 1.-Female, aged 5, presented every feature of the clinical aspects of true laryngeal diphtheria (Klebs-Loeffler), which was proven by microscopic diagnosis. This child had been ill three or four days before the physician was summoned; that foul odor so characteristic of the disease permeated the atmosphere of the whole house. Little did the writer think that this child's life could be saved, so livid were the lips, swollen the neck and stertorous the breathing. The vigorous use locally of the protonuclein special powder was immediately ordered every half hour; previous to the local use of protonuclein, this little patient could not swallow anything, was fast becoming comatose, and was with difficulty aroused sufficiently to allow the perfect administration of the remedies. After several insufflations of the powder, and during a violent cough ing spell, immense pieces of false membrane were thrown out; at this time the internal use of the 3-grain tablets every three hours was commenced. From this time on our patient made a rapid, uneventful recovery.

Case 2.-Female, aged 24, multipara. This case also gave every indication of true Klebs-Loeffler diphtheria, tonsillar and pharyngeal (diagnosis confirmed by culture and microscope). This patient also had chronic Bright's disease, from which she suffered periodically with general edema, etc. Several months previous to the attack of diphtheria, she had suffered as mentioned, and was placed upon the 3 -grain protonuclein tablets for three or four months, which was considerable time after the general dropsy had ceased. This patient now thought herself nearly well and discontinued the use of the tablets as above, when she was suddenly stricken with diphtheria; this was several weeks after the discontinuance of the protonuclein tablets. Strange to say, this case, though an adult, was nearly asphyxiated on account of the turgid mucous membrane; just at this time we were summoned in haste; protonuclein again scored a signal victory, after thorough and vigorous use locally and internally. Though on any treatment such a patient could scarcely be strong and well again, yet inside of two weeks our patient was up and attending to light household duties. In this family were two small children, aged respectively $21 / 2$ and 4 , who were constantly about the room and even slept in the same bed with their mother (the diphtheria case), both before and after the diagnosis was made. We immediately administered to each child a 3-grain tablet of protonuclein every three hours, and they did not contract the disease.

Case 3.--Klebs-Loeffler diphtheria (microscopic diagnosis), male, aged 23. This was a mild case, and under the control of the special powder locally and 3-grain tablets internally, made a complete recovery in eight days.

Case 4. - Streptococcus diphtheria (diagnosis by microscope) ; male, aged 7. This child has had since its second year similar attacks two or three times yearly. After a thorough application of the special powder locally and 3-grain tablets internally, we recorded a "good recovery," and now, though two years have elapsed since, there has been no return of the disease.

Case 5. - Female, aged 33, primipara, has usually had from one to two attacks of streptococcus diphtheria yearly for a number of years, until the last invasion of nearly two years since; was treated the same as Case 4.

Many more cases of both varieties of diphtheria could be cited, but these given are sufficient to explain our procedures. The beauty and immense value of the above methods in treating diphtheria is, firstly, you can begin exhibiting your remedy at once and be assured it will do no harm; hence, several hours of valuable time is not lost in waiting for a bacteriologist's report, besides, protonuclein will certainly cure both varieties of the scourge, barring possibly bad complications already in progress when the treatment is instituted.

In eczematous affections, or any epidermic (common ) disease except scabies, due to an organism, there is in our opinion nothing equal to the external and internal treatment with protonuclein, and occasionally-when the case demands it the hypodermic exhibition of the special powder (locally and hypo- 